\title{
The nature of the growth pattern and of the metabolic response to fasting in the rat are dependent upon the dietary protein and folic acid intakes of their pregnant dams and post-weaning fat consumption
}

\author{
Graham C. Burdge ${ }^{1}$, Karen A. Lillycrop ${ }^{2}$, Alan A. Jackson ${ }^{1}$, Peter D. Gluckman ${ }^{3}$ and Mark A. Hanson ${ }^{4}$ \\ ${ }^{1}$ Institute of Human Nutrition, University of Southampton, Southampton, SO16 6YD, UK \\ ${ }^{2}$ Development and Cell Biology, University of Southampton, Southampton SO16 7PX, UK \\ ${ }^{3}$ Liggins Institute, University of Auckland, Auckland, New Zealand \\ ${ }^{4}$ Centre for the Developmental Origins of Health and Disease, University of Southampton, Southampton SO16 6YD, UK \\ (Received 3 April 2007 - Revised 11 July 2007 - Accepted 11 July 2007)
}

\begin{abstract}
The nutritional cues which induce different phenotypes from a single genotype in developing offspring are poorly understood. How well prenatal nutrient availability before birth predicts that after birth may also determine the offspring's response to later metabolic challenge. We investigated the effect of feeding pregnant rats diets containing protein at $180 \mathrm{~g} / \mathrm{kg}$ (Control) or $90 \mathrm{~g} / \mathrm{kg}$ (protein-restricted, PR) and either $1 \mathrm{or} 5 \mathrm{mg}$ folic acid/ $\mathrm{kg}$ on growth and metabolic response to fasting in their offspring, and also the effect of diets with different fat contents (40 g/kg (Fat $\left.{ }_{4}\right)$ or $100 \mathrm{~g} / \mathrm{kg}$ $\left(\right.$ Fat $\left._{10}\right)$ ) after weaning. Offspring of dams fed the PR diet with $5 \mathrm{mg} / \mathrm{kg}$ folic acid were significantly lighter than other offspring. The PR offspring fed the Fat 4 diet had lower plasma TAG than the Control offspring, but this relationship was reversed when offspring were fed Fat ${ }_{10}$. Increasing the folic acid content of the Control or PR maternal diets induced opposing effects on plasma TAG, NEFA, $\beta$-hydroxybutyrate and glucose concentrations in offspring fed $\mathrm{Fat}_{4}$. The effect was accentuated in offspring fed the Fat ${ }_{10}$ diet such that these metabolites were increased in the Control offspring, but reduced in the PR offspring. These data show for the first time that maternal dietary folic acid intake alters offspring phenotype depending upon dietary protein intake, and that this effect is modified by fat intake after weaning. Prevention by increased folic acid intake of an altered metabolic phenotype by maternal protein-restriction may be at the expense of somatic growth.
\end{abstract}

Low-protein diet: Fetal programming: Folic acid: Growth: Metabolism

Developmental plasticity permits the induction of a range of phenotypes from a single genotype in response to environmental cues, thus increasing the probability of Darwinian fitness ${ }^{1-3}$. There is increasing evidence that variations in the intra-uterine environment, including nutrition and stress hormones, modify the metabolic and physical development of the fetus and so induce different phenotypes in the offspring ${ }^{4}$. Even in the normal range of development, these processes may have longterm effects in terms of graded changes in risk of metabolic diseases and CVD in man, which has been termed fetal programming $^{5,6}$. Subsequently, it has been suggested that environmental cues acting via developmental plasticity induce phenotypes which predict the environment experienced after birth, thus not only maximising Darwinian fitness but also preserving genotypic variation during short-term environmental challenge $\mathrm{e}^{1,2,7}$. Induction of a phenotype which incorrectly predicts the postnatal environment may thus lead to a later disadvantage. In man such mismatch between the predicted and actual postnatal environment may increase risk of metabolic disease $e^{3,7,8}$. However, induction of a phenotype which confers a survival and reproductive advantage may involve developmental trade-offs such as reduced growth ${ }^{9}$ which would be disadvantageous in other circumstances. It is therefore important to understand the nature of the environmental cues and the mechanisms by which different phenotypes are induced.

A number of environmental cues acting during development, including nutrition, which induce a predictive adaptive response have been identified in several species ${ }^{1,10-12}$. For example, in the rat, global nutrient restriction ${ }^{13}$, or alterations in the amount of specific nutrients in the maternal diet (MD) such as reduced protein ${ }^{14,15}$ or increased fat ${ }^{16}$ during pregnancy and/or lactation modify the metabolic phenotype of the offspring. For example, feeding a protein-restricted (PR) diet to pregnant rats induces in the offspring hypertension, dyslipidaemia and insulin resistance ${ }^{14,15,17}$. Recent evidence suggests that induction of dyslipidaemia and impaired glucose homeostasis in the offspring by a maternal PR diet involves altered epigenetic regulation of specific transcription factors in the liver ${ }^{18-20}$ as a

Abbreviations: CF, Control diet supplemented with additional folic acid; Fat ${ }_{4}$ diet, diet with $40 \mathrm{~g}$ fat $/ \mathrm{kg}$; Fat ${ }_{10}$ diet, diet with $100 \mathrm{~g}$ fat $/ \mathrm{kg}$; BHB, $\beta$-hydroxybutyrate; MD, maternal diet; PR diet, protein-restricted diet; PRF, PR diet supplemented with additional folic acid; PWD, post-weaning diet.

* Corresponding author: Dr G. C. Burdge, Institute of Human Nutrition, Institute of Developmental Sciences Building, Southampton General Hospital, Mail Point 887, Tremona Road, Southampton SO16 6YD, UK, fax +44(0)2380 795255, email g.c.burdge@soton.ac.uk 
result of reduced DNA methyltransferase- 1 expression and promoter binding ${ }^{19}$. Impaired vascular function ${ }^{21-23}$ may also reflect, at least in part, altered epigenetic regulation of transcription factors in the heart and peripheral vasculature ${ }^{20}$. The mechanism by which reduced protein intake during pregnancy changes the epigenetic regulation of genes in offspring and leads to an altered phenotype from a single genotype is not understood, although altered 1-carbon metabolism appears to be central to this process ${ }^{20}$. For example, increasing the amount of glycine or folic acid, but not alanine or urea, in the PR diet prevented hypertension ${ }^{21-23}$, altered epigenetic regulation of transcription factors ${ }^{18}$ and reduced DNA methyltransferase- 1 expression and activity ${ }^{19}$ in the liver of the offspring.

One possible interpretation of these findings is that the developmental cues which result in induction of altered epigenetic regulation of specific genes and of alternative phenotypes in the offspring involves an interaction between the amount of protein and folic acid in the diet of pregnant dams. Here we have tested this hypothesis. We have investigated the effect of feeding diets with different amounts of protein $(180$ or $90 \mathrm{~g} / \mathrm{kg} \mathrm{w} / \mathrm{w})$ with either 1 or $5 \mathrm{mg}$ folic acid $/ \mathrm{kg}$ throughout pregnancy on the phenotype of the offspring. Phenotypes were described in terms of growth, and the concentrations of lipids and glucose in blood in response to fasting since feeding a PR diet to pregnant dams induces dyslipidaemia, insulin resistance and increased gluconeogenesis in the offspring ${ }^{15,17}$. To test the hypothesis that match or mismatch in nutrient availability between the prenatal and postnatal environment also influences growth and metabolic phenotype of the offspring, they were fed from weaning diets with different fat contents (40 or $100 \mathrm{~g} / \mathrm{kg}$ ) which were within the physiological range for the $\mathrm{rat}^{24}$. This allows these hypotheses to be tested in the context of the effects of variation in prenatal and postnatal nutrition within the normal range on growth and metabolic capacity in $\operatorname{man}^{5,6}$.

\section{Materials and methods}

\section{Animal procedures}

The study was carried out in accordance with the Home Office Animals (Scientific Procedures) Act (1986). The diets fed during pregnancy were essentially as described previously ${ }^{14,18}$ with the exception that soyabean oil was used instead of maize oil in order to provide sufficient $\alpha$-linolenic acid ${ }^{24}$. Virgin female Wistar rats were mated and fed one of four diets from conception until delivery (each group contained six females): Control (180 g protein/kg plus $1 \mathrm{mg}$ folic acid/kg); Control supplemented with additional folic acid (CF, $180 \mathrm{~g}$ protein/ $\mathrm{kg}$ plus $5 \mathrm{mg}$ folic acid/kg); a PR diet (90 g casein/kg plus $1 \mathrm{mg}$ folic acid/kg); or PR supplemented with additional folic acid (PRF; $90 \mathrm{~g}$ casein/ $\mathrm{kg}$ plus $5 \mathrm{mg}$ folic acid $/ \mathrm{kg}$ ). Diets were manufactured by Special Diets Services. Table 1 summarises the nutrient composition of the MD. The difference in the folic acid content between diets is equivalent to the increment in folic acid intake which women in the UK are advised to consume to prevent neural tube defects ${ }^{25}$. Dams were weighed before mating and at $7 \mathrm{~d}$ intervals throughout pregnancy. Food intake over $24 \mathrm{~h}$ was assessed on post-conceptional day 19. After spontaneous delivery on approximately post-conceptional day 21 , litters were reduced to eight pups. Dams were fed AIN-76G diet (Special Diets Services) throughout lactation. The weights of litters containing eight pups were recorded on postnatal day 1 and at $7 \mathrm{~d}$ intervals until weaning. The pups were weaned on to a diet containing $40 \mathrm{~g}$ fat $/ \mathrm{kg}\left(\mathrm{Fat}_{4}\right)$ or a diet containing $100 \mathrm{~g}$ fat $/ \mathrm{kg}\left(\mathrm{Fat}_{10}\right)$ on postnatal day 28 (Table 1). The fat component of both post-weaning diets (PWD) was composed of lard-soyabean oil (9:1, w/w). Each PWD group contained twelve males and twelve females from each MD group. The offspring of the Control MD group which were fed the Fat $_{4}$ diet after weaning were used as reference group since this combination of diets resembled most closely that recommended for pregnancy, growth and maintenance of

Table 1. Compositions of diets fed to pregnant and lactating dams, and to the offspring after weaning

\begin{tabular}{|c|c|c|c|c|c|c|c|}
\hline & \multicolumn{4}{|c|}{ Diet fed during pregnancy* } & \multirow{2}{*}{$\begin{array}{l}\text { Diet fed during lactation } \\
\text { AIN-76G }\end{array}$} & \multicolumn{2}{|c|}{$\begin{array}{c}\text { Post-weaning } \\
\text { diet† }\end{array}$} \\
\hline & Control & $\mathrm{CF}$ & PR & PRF & & $\mathrm{Fat}_{4}$ & $\mathrm{Fat}_{10}$ \\
\hline Casein $(\mathrm{g} / \mathrm{kg})$ & 180 & 180 & 90 & 90 & 200 & 180 & 180 \\
\hline Folic acid (mg/kg) & 1 & 5 & 1 & 5 & 2 & 1 & 1 \\
\hline Maize starch (g/kg) & 425 & 425 & 485 & 485 & 150 & 455 & 425 \\
\hline Sucrose $(\mathrm{g} / \mathrm{kg})$ & 213 & 213 & 243 & 243 & 500 & 243 & 213 \\
\hline Choline $(\mathrm{g} / \mathrm{kg})$ & 2 & 2 & 2 & 2 & 2 & 2 & 2 \\
\hline Methionine $(\mathrm{g} / \mathrm{kg})$ & 5 & 5 & 5 & 5 & 3 & 5 & 5 \\
\hline Vitamin mix $(\mathrm{g} / \mathrm{kg}) \ddagger$ & 5 & 5 & 5 & 5 & 5 & 5 & 5 \\
\hline Mineral mix $(\mathrm{g} / \mathrm{kg}) \S$ & 20 & 20 & 20 & 20 & 20 & 20 & 20 \\
\hline Cellulose $(\mathrm{g} / \mathrm{kg})$ & 50 & 50 & 50 & 50 & 50 & 50 & 50 \\
\hline Maize oil $(\mathrm{g} / \mathrm{kg})$ & Nil & Nil & Nil & Nil & 50 & Nil & Nil \\
\hline Soyabean oil (g/kg) & 100 & 100 & 100 & 100 & Nil & 4 & 10 \\
\hline Lard $(g / k g)$ & Nil & Nil & Nil & Nil & Nil & 36 & 90 \\
\hline Total metabolisable energy $(\mathrm{MJ} / \mathrm{kg})$ & $17 \cdot 3$ & $17 \cdot 3$ & $17 \cdot 5$ & $17 \cdot 5$ & $15 \cdot 5$ & $16 \cdot 1$ & $17 \cdot 3$ \\
\hline
\end{tabular}

${ }^{*}$ Control, $180 \mathrm{~g}$ protein $/ \mathrm{kg}, 1 \mathrm{mg}$ folic acid $/ \mathrm{kg} ; \mathrm{CF}, 180 \mathrm{~g}$ protein $/ \mathrm{kg}, 5 \mathrm{mg}$ folic acid $/ \mathrm{kg} ; \mathrm{PR}, 90 \mathrm{~g}$ protein $/ \mathrm{kg}, 1 \mathrm{mg}$ folic acid $/ \mathrm{kg} ; \mathrm{PRF}, 90 \mathrm{~g} \mathrm{protein} / \mathrm{kg}$ $5 \mathrm{mg}$ folic acid $/ \mathrm{kg}$

†Fat 4 , 40 fat $\mathrm{g} / \mathrm{kg} ;$ Fat $_{10}, 100 \mathrm{~g}$ fat $/ \mathrm{kg}$.

‡Thiamine hydrochloride $2.4 \mathrm{mg} / \mathrm{kg}$; riboflavin $2.4 \mathrm{mg} / \mathrm{kg}$; pyridoxine hydrochloride $2.8 \mathrm{mg} / \mathrm{kg}$; nicotinic acid $12.0 \mathrm{mg} / \mathrm{kg}$; D-calcium pantothenate $6.4 \mathrm{mg} / \mathrm{kg}$; biotin $0.01 \mathrm{mg} / \mathrm{kg}$; cyanocobalamin $0.003 \mathrm{mg} / \mathrm{kg}$; retinyl palmitate $6.4 \mathrm{mg} / \mathrm{kg}$; DL- $\alpha$-tocopherol acetate $79.9 \mathrm{mg} / \mathrm{kg} ; \mathrm{cholecalciferol} 1.0 \mathrm{~g} / \mathrm{kg}$; menaquinone $0.02 \mathrm{mg} / \mathrm{kg}$.

$\S$ Calcium phosphate dibasic $11.3 \mathrm{~g} / \mathrm{kg}$; sodium chloride $1.7 \mathrm{~g} / \mathrm{kg}$; potassium citrate monohydrate $5.0 \mathrm{~g} / \mathrm{kg}$; potassium sulphate $1.2 \mathrm{~g} / \mathrm{kg}$; magnesium sulphate $0.5 \mathrm{~g} / \mathrm{kg}$; magnesium carbonate $0.1 \mathrm{~g} / \mathrm{kg}$; ferric citrate $0.1 \mathrm{~g} / \mathrm{kg}$; zinc carbonate $36.2 \mathrm{mg} / \mathrm{kg}$; cupric carbonate $6.8 \mathrm{mg} / \mathrm{kg}$; potassium iodate $0.2 \mathrm{mg} / \mathrm{kg}$; sodium selenite $0.2 \mathrm{mg} / \mathrm{kg}$; chromium potassium sulphate $12.5 \mathrm{mg} / \mathrm{kg}$. 
rats $^{24}$. Offspring were weighed at $7 \mathrm{~d}$ intervals and food intake over $24 \mathrm{~h}$ was measured at $25 \mathrm{~d}$ intervals. On postnatal day 105 , food was withdrawn at about 08.00 hours, but water was available ad libitum, and offspring were killed by asphyxiation with $\mathrm{CO}_{2} 6 \mathrm{~h}$ later. Blood was collected by cardiac puncture into tubes containing EDTA. Plasma was separated from cells by centrifugation and stored at $-80^{\circ} \mathrm{C}$. Livers and hearts were removed immediately and weighed.

\section{Measurements of metabolites in blood}

Plasma TAG, NEFA, $\beta$-hydroxybutyrate $(\beta \mathrm{HB})$ and glucose concentrations were measured as described ${ }^{26}$ using a Konelab 20 autoanalyser $^{26}$. Within-assay $\mathrm{CV}$ were TAG $<2 \%$, NEFA $<2 \%, \beta \mathrm{HB}<1 \%$ and glucose $<2 \%$. Between-assay $\mathrm{CV}$ were $\mathrm{TAG}<3 \%$, NEFA $<5 \%, \beta \mathrm{HB}<2 \%$ and glucose $<4 \%$.

\section{Statistical analysis}

Statistical analysis was carried out using SPSS version 14.0 for Windows (SPSS Inc., Chicago, IL, USA). Analysis using the Shapiro-Wilks test showed that none of the measurements differed significantly from a normal distribution. The effect of MD and PWD on body weight over time was assessed by a General Linear Model with repeated measures with time as a within-subject factor, and MD, sex of the offspring and PWD as betweensubject factors where appropriate. The effect of MD and PWD on the concentrations of metabolites in blood and on liver and heart weights was assessed by a General Linear Model with MD, sex of the offspring and PWD as between-subject factors. Bonferroni's correction for multiple comparisons was used for all post hoc testing. Pair-wise comparisons were by Student's unpaired $t$ test. Hierarchical analysis of the effects of the fixed factors on the major outcome variables was carried out by multiple linear regression.

\section{Results}

\section{Maternal weight and food intake}

There were no significant differences in the weights of the dams before mating between MD groups to which they were assigned after conception (Fig. 1(A)). Two-way ANOVA with repeated measures showed that there was a significant effect of time $(P<0.001)$, but not MD, on the weight of the dams during pregnancy. Food intake over $24 \mathrm{~h}$ on post-conceptional day 19 did not differ between MD groups (Control 17.5 (SD2.5) g, CF 17.5 (SD 1.7) g, PR 16.3 (SD 3.1) g and PRF 15.5 (SD 3.6) g). There were no significant differences in litter size between MD groups (Control 11 (SD 3); CF 12 (SD 2); PR 11 (SD 2); PRF 11 (SD 3)). There was no significant effect of time or MD on maternal weight after delivery (Fig. 1(B)).

\section{Growth of the offspring before weaning}

There were no significant differences between MD groups in neonatal litter weight (eight offspring per group, equal numbers of males and females; Fig. 1(C)). There was a significant effect of time $(F(4,19) 629.4 ; P<0.0001)$ and MD $(F(3,19)$ $4.6 ; P<0 \cdot 020)$, and a significant interactive effect between age and $\mathrm{MD}(F(3,19) 5 \cdot 1, P<0.001)$ on the weight of the offspring after birth (Fig. 1(C)). There were no significant differences in litter weight between MD groups on days 7 and 14. However, the PRF group was significantly $(P<0.05)$ lighter compared to the other MD groups on postnatal day 21 (22\% compared to the Control group) and day $28(30 \%$ compared to the Control group) (Fig. 1(C)). Overall weight gain of the PRF offspring (386 (SD 30) g over $28 \mathrm{~d}$ ) was significantly less $(23-32 \% ; P<0.005)$ than the offspring of the other MD groups (Control 564 (SD 55) g; CF 481 (SD 87) g; $9 \% 473$ (SD 84) g over $28 \mathrm{~d}$ ).

\section{Growth and food consumption of the offspring after weaning}

The male PRF offspring were significantly lighter $(P=0.004)$ at weaning compared to males in other MD groups (e.g. the PRF Fat ${ }_{4}$ PWD group was $17 \%$ lighter and PRF Fat 10 PWD group $22 \%$ lighter than the Control $\mathrm{Fat}_{4}$ PWD group), while there was no significant difference between female offspring according to MD group (Fig. 2). There was a significant effect of time after weaning $(F(11,155) 8444 \cdot 7, P<0.0001)$, sex $(F(1,155) 35 \cdot 7, P=0.027), \operatorname{MD}(F(3,155) 7 \cdot 3, P=0 \cdot 017)$, but not PWD, and a significant interactive effect $(F(3,155)$ $4.3, P<0.0001)$ of post-weaning age and MD, but not PWD, on the weight of the offspring after weaning. For males, body weight of the PRF Fat 4 PWD and PRF Fat 10 PWD groups was significantly lower compared to the other groups throughout the post-weaning period $(P<0.05$ at all timepoints), while there was no significant difference in body weight between the male offspring of the Control, $\mathrm{CF}$ and PR MD groups (Fig. 2). Overall, weight gain between postnatal ages 28 and $105 \mathrm{~d}$ in the PRF Fat ${ }_{4}$ PWD group was $15 \%$ lower and the PRF Fat ${ }_{10}$ PWD group $16 \%$ lower than the Control Fat 4 PWD group $(P=0.022)$. For females, body weight did not differ between groups until postnatal day 42 at which the weight of the PRF groups were significantly lower $(P<0.05)$ than the other groups (Fig. 2). Overall, weight gain after weaning was $10 \%$ lower in the PRF Fat PWD females and $11 \%$ lower in the PRF Fat ${ }_{10}$ PWD females compared to the Control Fat ${ }_{4}$ PWD females $(P=0 \cdot 019)$.

There was no significant effect of time after-weaning, MD or PWD on the amount of food consumed per $100 \mathrm{~g}$ body weight per day by the offspring. Males fed the Fat $_{4}$ PWD diet consumed between 5.2 and $7.4 \mathrm{~g}$, males fed the Fat 10 PWD consumed between 5.3 and $7 \cdot 1 \mathrm{~g}$, females fed the Fat PWD diet consumed between 5.3 and $6.9 \mathrm{~g}$, and females fed the Fat $_{10}$ PWD diet consumed between 5.0 and 6.6 g.

\section{Weight of the heart and liver of the offspring at postnatal day 105}

The heart accounted for $0.5-0.6 \%$ of body weight in males and $0.6-0.64 \%$ of body weight in females. Liver accounted for $3 \cdot 1-3.6 \%$ of body weight in males and $3 \cdot 3-3.6 \%$ of body weight in females. There was no significant effect of $\mathrm{MD}$, sex of the offspring or PWD on the weight of the heart or liver when expressed as a proportion of body weight.

\section{Blood lipid and glucose concentrations in the offspring}

Concentrations of metabolites in blood from male offspring are summarised in Fig. 3 and females in Fig. 4. There was a 

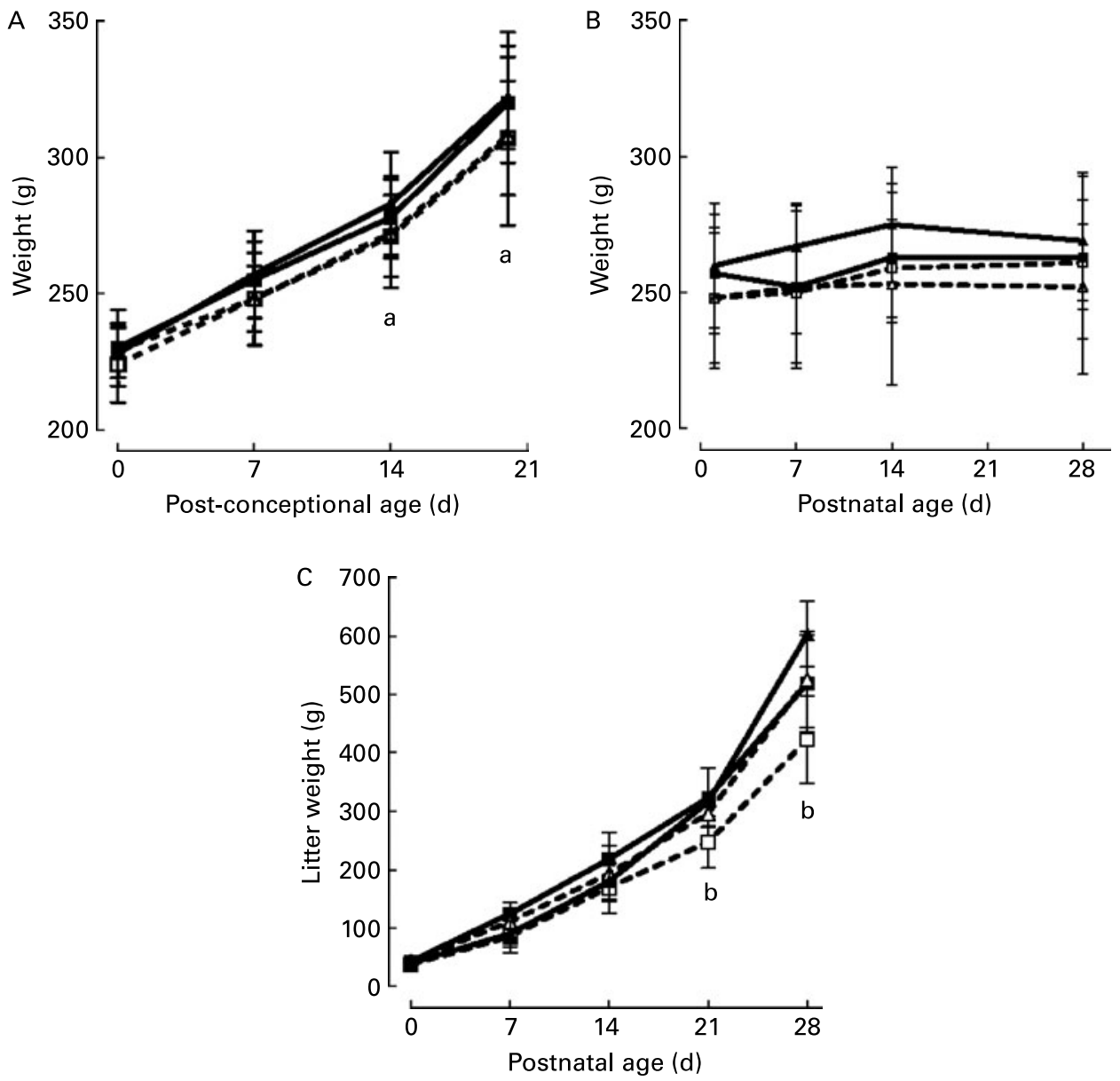

Fig. 1. Maternal weights (six per dietary group) during pregnancy (A) and lactation (B). (C), Litter weights (six litters, eight offspring, equal males and females, per litter) during suckling according to maternal dietary group. Maternal diets were: Control ( $\mathbf{\Lambda}, 180 \mathrm{~g} \mathrm{protein} / \mathrm{kg}, 1 \mathrm{mg}$ folic acid $/ \mathrm{kg}$ ); CF ( $\triangle, 180 \mathrm{~g} \mathrm{protein} / \mathrm{kg}, 5 \mathrm{mg}$ folic acid/kg); PR ( $\square, 90 \mathrm{~g}$ protein $/ \mathrm{kg}, 1 \mathrm{mg}$ folic acid $/ \mathrm{kg})$; PRF ( $\square, 90 \mathrm{~g}$ protein $/ \mathrm{kg}, 5 \mathrm{mg}$ folic acid/kg). Values are means with standard deviations depicted by vertical bars. ${ }^{a}$ Time-points at which the weight of the dams was significantly different $(P<0.05)$ from pre-pregnant weight or weight on post-partum day 1 by a General Linear Model with Bonferroni's post hoc test. ${ }^{b}$ Time-points at which the weight of the PRF offspring was significantly different $(P<0.05)$ from the other groups by a General Linear Model with Bonferroni's post hoc test.

significant effect of offspring sex $(F(1,140) 53 \cdot 8, P<0 \cdot 0001)$, PWD $(F(1,140) \quad 12 \cdot 7, P=0 \cdot 001)$ and $\operatorname{MD}(F(3,140) 24 \cdot 1$, $P<0.0001)$, and significant interactive effects of PWD and MD $(F(1,140) 16.4, \quad P<0.0001)$, offspring sex and MD $(F(1,140) 3 \cdot 2, \quad P=0 \cdot 011)$ on plasma TAG concentration. There was a significant effect of offspring sex $(F(1,140) 4 \cdot 0$, $P=0.048)$ and $\mathrm{MD}(F(3,140) 17 \cdot 5, P<0 \cdot 0001)$ during pregnancy, but not PWD or interactive effects, on plasma NEFA concentration. There was a significant effect of MD $(F(3,140) 25 \cdot 0, P<0 \cdot 0001)$, PWD $(F(1,140) 11 \cdot 1, P=0 \cdot 001)$ and sex of the offspring $(F(1,140) 6 \cdot 8, P=0 \cdot 01)$, and a significant interactive effect of MD and PWD $(F(3,140) 5 \cdot 4$, $P=0.002)$ on plasma $\beta \mathrm{HB}$ concentration in plasma. There was a significant effect of $\mathrm{MD}(F(3,140) 7 \cdot 5, P<0 \cdot 0001)$ and PWD $(F(1,140) 20.7, P<0.0001)$, but not the sex of the offspring, and a significant interactive effect of $\mathrm{MD}$ and PWD $(F(3,140) \quad 8.0, \quad P<0.0001)$ on plasma glucose concentration.

Male and female offspring showed a similar pattern of differences in plasma lipid and glucose concentrations for each combination of MD and PWD (Figs. 3 and 4). The effects of maternal protein and folic acid intakes on the offspring fed the Fat ${ }_{4}$ PWD will be described first. Increasing the folic acid content of the Control MD diet (CF group) was associated with a higher (24\%) plasma TAG concentration (Fig. 3). This was accompanied by higher (77\%) plasma NEFA concentration, while there were no significant differences in $\beta \mathrm{HB}$ or glucose concentrations (Fig. 3). A reduction in maternal protein intake to PR was associated with lower (29\%) plasma TAG concentration relative to the offspring of the Control dams, while the concentrations of plasma NEFA, $\beta \mathrm{HB}$ and glucose were higher in the offspring of the PR group (88, 47 and $33 \%$, respectively; Fig. 3). Increasing the folic acid content of the PR diet resulted in lower plasma TAG concentration compared to the offspring of the Control dams (31\%) and the CF dams (62\%), but did not differ from the PR group (Fig. 3). The concentrations of plasma NEFA, $\beta \mathrm{HB}$ and glucose did not differ from the Control group, but plasma NEFA concentration was $37 \%$ lower than the CF group (Fig. 3).

Increasing fat intake after weaning induced specific differences in the concentrations of individual metabolites in blood in males and females (Figs. 3 and 4). There was no difference in plasma TAG concentration between male 

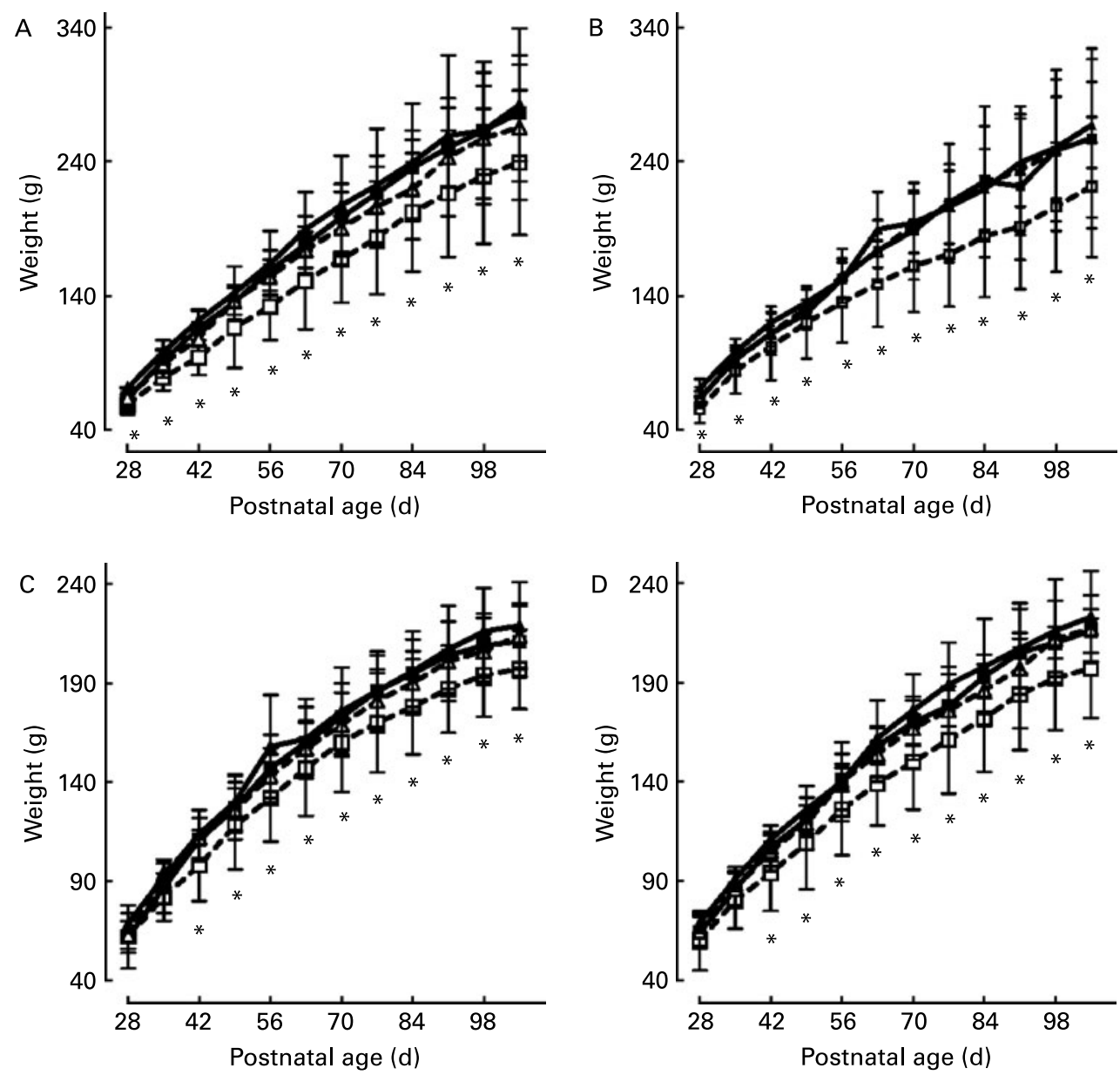

Fig. 2. Weights of offspring after weaning (twelve males or females per post-weaning dietary group) according to maternal dietary group. (A), Male offspring, $40 \mathrm{~g}$ fat $/ \mathrm{kg}$ post-weaning diet (PWD); (B), male offspring, $100 \mathrm{~g}$ fat $/ \mathrm{kg}$ PWD; (C), female offspring, $40 \mathrm{~g}$ fat $/ \mathrm{kg}$ PWD; (D), female offspring, $100 \mathrm{~g}$ fat $/ \mathrm{kg}$ PWD. Maternal

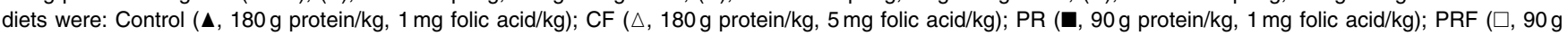
protein $/ \mathrm{kg}, 5 \mathrm{mg}$ folic acid $/ \mathrm{kg}$ ). Values are means with standard deviations depicted by vertical bars. ${ }^{*}$ Time-points at which the weight of the PRF offspring was significantly different $(P<0.05)$ from the other groups using a General Linear Model with Bonferroni's post hoc test.

offspring of the Control, CF and PRF dams which were fed the Fat $_{4}$ PWD and those fed the Fat ${ }_{10}$ PWD (Fig. 3). However, the concentration of plasma TAG was $69 \%$ higher than the corresponding offspring of the Control dams, and $125 \%$ higher $(P<0.0001)$ than the offspring of PR dams fed the $\mathrm{Fat}_{4}$ PWD. Thus, feeding a PWD with a higher fat content reversed the relationship between the offspring of the Control dams and PR dams. There was no effect of the amount of fat in the PWD on plasma NEFA concentration (Fig. 3). However, plasma $\beta \mathrm{HB}$ concentration was higher $(103 \%)$ in the offspring of the CF dams when fed the Fat ${ }_{10}$ PWD compared to corresponding offspring fed the $\mathrm{Fat}_{4}$ PWD (Fig. 3). Plasma glucose concentration was also higher $(25 \%)$ in the offspring of the $\mathrm{CF}$ dams when fed the Fat ${ }_{10}$ PWD compared to corresponding offspring fed the $\mathrm{Fat}_{4}$ PWD.

Multiple linear regression analysis showed that differences in MD accounted for $17 \%$ of the variation in TAG concentration $(P=0.035), 31 \%$ of the variation in NEFA concentration $(P<0.0001)$ and $10 \%$ of the variation in $\beta \mathrm{HB}$ concentration $(P=0.022)$, but did not predict significantly variation in glucose concentration. Differences in sex accounted for $22 \%$ of the variation in TAG concentration
$(P=0.002), 20 \%$ of the variation in NEFA concentration $(P<0.0001)$ and $6 \%$ of the variation in $\beta \mathrm{HB}$ concentration $(P=0.015)$, but did not predict significantly variation in glucose concentration. Differences in fat intake after weaning accounted for $58 \%$ of the variation in plasma TAG concentration $(P<0.0001), 20 \%$ of the variation in NEFA concentration $(P<0.0001), 52 \%$ of the variation in $\beta \mathrm{HB}$ concentration $(P=0.007)$ and $9 \%$ of the variation in glucose concentration $(P=0.004)$.

\section{Discussion}

The results of the present study show for the first time that increasing the folic acid content of the MD induced opposing changes in the metabolic response to fasting in the offspring depending on the protein content of the MD. When offspring were fed the $\mathrm{Fat}_{4}$ diet, offspring of the $\mathrm{CF}$ group showed either an increase in the concentrations of specific metabolites or no change compared to Control offspring, while offspring of the PRF group showed either a decrease in the concentrations of specific metabolites or no change compared to PR offspring. These effects were accentuated by increasing the fat content 
Males
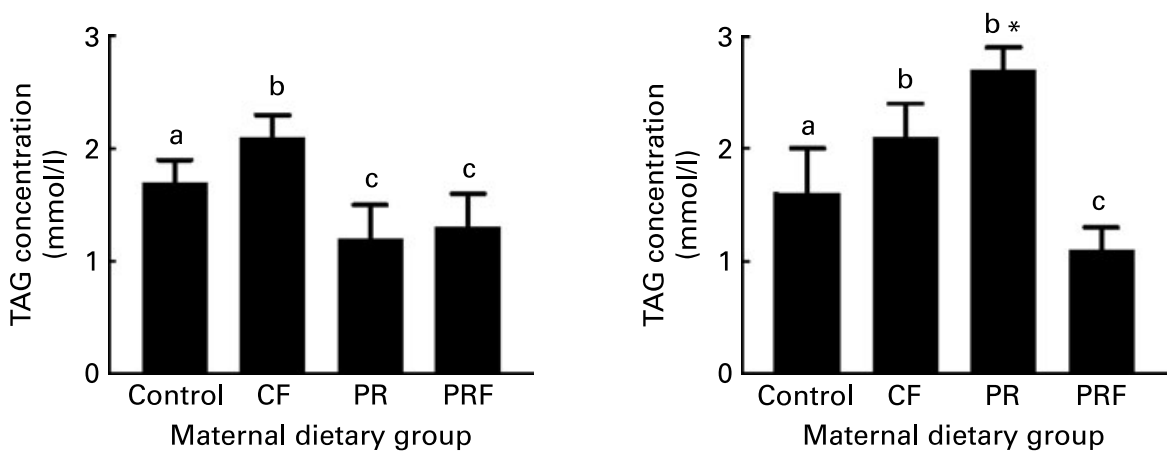

$\mathrm{Fat}_{4}$
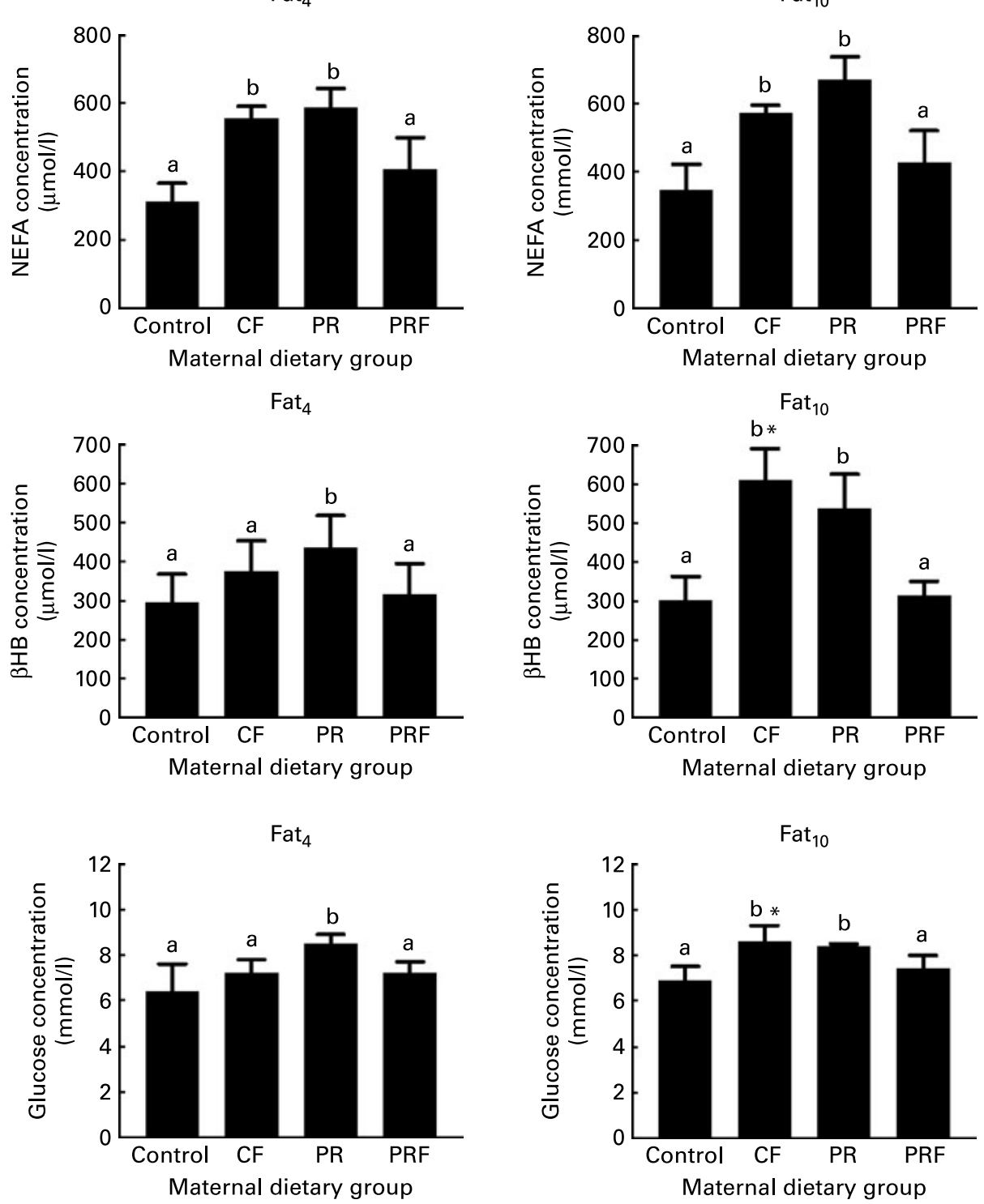

Fig. 3. Concentrations of metabolites in blood from male offspring at $105 \mathrm{~d}$ after weaning. Maternal diets were: Control (180 g protein/kg, $1 \mathrm{mg}$ folic acid/kg); CF (180 g protein $/ \mathrm{kg}, 5 \mathrm{mg}$ folic acid/kg); PR (90 g protein $/ \mathrm{kg}, 1 \mathrm{mg}$ folic acid $/ \mathrm{kg}$ ); PRF ( $90 \mathrm{~g}$ protein $/ \mathrm{kg}, 5 \mathrm{mg}$ folic acid $/ \mathrm{kg}$ ). Post-weaning diets (PWD) were: Fat 4 (40 fat $\mathrm{g} / \mathrm{kg}$ PWD) or Fat 10 (100 g fat/kg PWD). Values are means with standard deviations depicted by vertical bars $(n 12)$. ${ }^{a, b, c}$ Mean values with unlike superscript letters were significantly different $(P<0.05)$ from the other groups of offspring fed the same PWD using a General Linear Model with Bonferroni's post hoc test. For each metabolite within a PWD group, there was a significant difference $(P<0.0001)$ between maternal dietary groups. Mean values were significantly different between PWD for offspring of dams fed the same diet during pregnancy (Student's unpaired $t$ test): ${ }^{*} P<0.05$. $\beta \mathrm{HB}$, plasma $\beta$-hydroxybutyrate. 


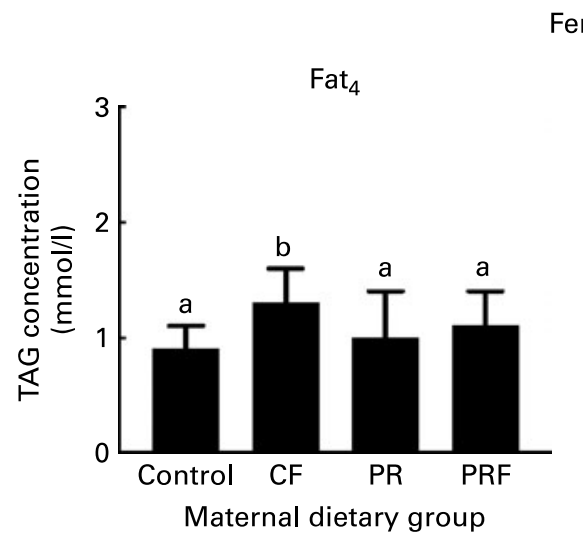

Females
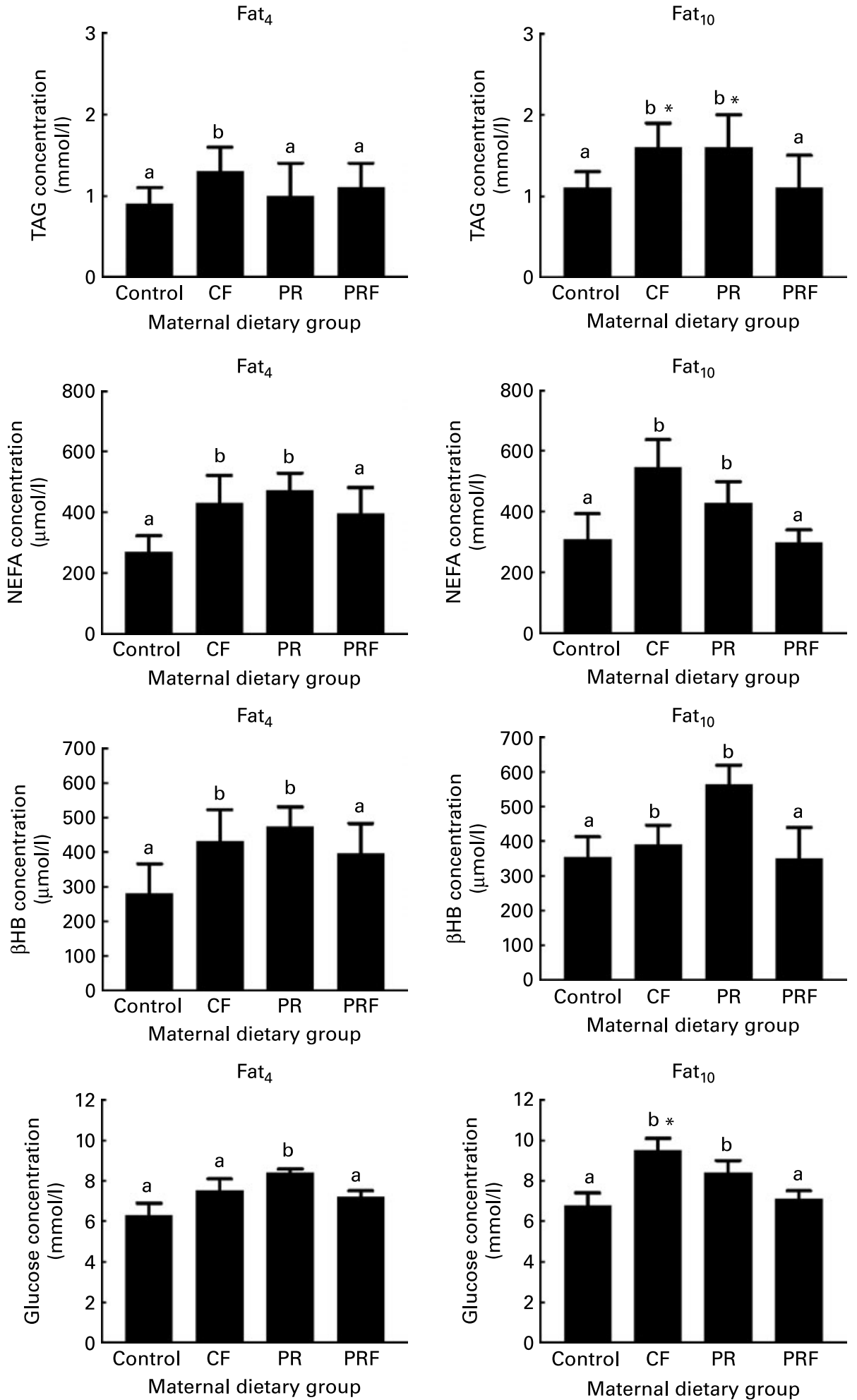

Fig. 4. Concentrations of metabolites in blood from female offspring at $105 \mathrm{~d}$ after weaning. Maternal diets were: Control (180 $\mathrm{g}$ protein $/ \mathrm{kg}$, $1 \mathrm{mg}$ folic acid/ $\mathrm{kg}$ ); CF (180 g protein $/ \mathrm{kg}, 5 \mathrm{mg}$ folic acid $/ \mathrm{kg})$; PR ( $90 \mathrm{~g}$ protein $/ \mathrm{kg}, 1 \mathrm{mg}$ folic acid $/ \mathrm{kg})$; PRF $(90 \mathrm{~g}$ protein $/ \mathrm{kg}, 5 \mathrm{mg}$ folic acid $/ \mathrm{kg})$. Post-weaning diets (PWD) were: Fat 4 (40 fat $\mathrm{g} / \mathrm{kg}$ PWD) or Fat 10 (100 g fat/kg PWD). Values are means with standard deviations depicted by vertical bars $(n 12)$. ${ }^{a, b}$ Mean values with unlike superscript letters were significantly different $(P<0.05)$ from the other groups of offspring fed the same PWD using a General Linear Model with Bonferroni's post hoc test. For each metabolite within a PWD group, there was a significant difference $(P<0.0001)$ between maternal dietary groups. Mean values were significantly different between PWD for offspring of dams fed the same diet during pregnancy (Student's unpaired $t$ test): ${ }^{\star} P<0.05$. $\beta \mathrm{HB}$, plasma $\beta$-hydroxybutyrate. 
of the PWD. However, normalisation of the concentrations of lipid metabolites and glucose in the offspring of the PRF dams appeared to be at the expense of growth.

There was no effect of consuming the four experimental diets on the weight gain of the dams during pregnancy, on their appetite, on reproductive capacity indicated by litter size or on maternal weight during lactation. There was no indication of the adverse effects on maternal weight gain and appetite during pregnancy, or on litter weight at birth reported when pregnant rats were fed diets containing eightfold more folic acid than the highest amount used in the present study $^{27,28}$.

The four different combinations of protein and folic acid in the MD induced phenotypes in the offspring which differed in their patterns of growth and metabolic response to fasting. The offspring of the Control group of dams achieved adult weights in the expected range for males and females ${ }^{29}$, and responded to fasting by maintaining concentrations of blood lipids, ketone bodies and glucose within the expected range ${ }^{30}$ irrespective of PWD. The offspring of the PR dams fed the Fat diet showed increased concentrations of NEFA, $\beta \mathrm{HB}$ and glucose, but lower TAG concentration during fasting compared to the Control offspring. One possible explanation is that the MD resulted in increased NEFA release by adipose tissue, possibly due to impaired PPAR $\gamma 2$ activity ${ }^{17}$. Plasma NEFA are an important source of fatty acids for hepatic TAG biosynthesis $^{31,32}$. However, it is possible that the lower fasting TAG concentration may have been due to compensation of the increased flux of NEFA to the liver by up-regulation of hepatic fatty acid $\beta$-oxidation ${ }^{17,18}$. The elevated glucose concentration may reflect increased glucose synthesis by the gluconeogenic pathway ${ }^{15}$ and/or insulin resistance.

Increasing the folic acid content of the MD induced opposing effects on the concentrations of lipid metabolites and glucose in blood in the offspring depending upon the amount of protein in the MD. When dams consumed a diet containing the Control amount of protein, increasing the amount of folic acid selectively increased the concentration of TAG and NEFA in the offspring, while other metabolites remained unchanged. Conversely, when dams consumed the PR diet, increasing the amount of folic acid tended to decrease the concentrations of NEFA, $\beta \mathrm{HB}$ and glucose while TAG concentration remained unchanged. Overall, increasing the amount of nutrients involved in one-carbon metabolism in the MD, specifically glycine or folic acid, tends to normalise the response of lipid and carbohydrate metabolism in the offspring to fasting as shown by the present data, and to prevent hypertension and impaired vascular function ${ }^{21-23}$, and impaired epigenetic regulation of genes ${ }^{18}$ when dams were fed a PR diet. However, the present data suggest such beneficial effects, at least on lipid and glucose metabolism, are lost when dams are fed a protein-sufficient diet. This pattern was accentuated when the offspring were fed the Fat ${ }_{10}$ PWD such that when dams were fed the Control diet, increasing folic acid intake increased the concentrations of lipid metabolites and glucose in the blood of the offspring. Conversely, increasing the folic acid content of the PR diet tended to normalise the concentrations of these metabolites. The present data are in agreement with the observation that increasing the folic acid content of a maternal PR diet prevented hypertension in the offspring, while increasing the folic acid content of the protein-sufficient diet increased the blood pressure of the offspring $^{33}$.

There was no effect of increasing fat intake after weaning on plasma TAG concentration in the offspring of the dams fed the Control diet. However, feeding the Fat ${ }_{10}$ PWD resulted in a higher concentration of plasma TAG in the offspring of dams fed the PR diet, possibly reflecting the amount of fatty acids available to the liver exceeding the capacity for $\beta$-oxidation since there was no increase in $\beta \mathrm{HB}$ concentration. It may be assumed that the offspring of the dams fed the Control diet experienced an appropriate nutritional environment before birth, while the offspring of dams fed the PR diet experienced a poor nutritional environment. If so, then the offspring of the Control group appeared to respond appropriately to a nutrientrich environment, while the PR offspring were less well adapted. Together the preent findings are consistent with the environmental mismatch hypothesis ${ }^{7}$.

Although the addition of folic acid to the PR diet appeared to normalise the concentrations of lipid metabolites and glucose in the blood of the offspring, this appeared to be at the expense of growth which was lower at weaning in males, and from postnatal day 42 in females. The latter may have been due to slower weight gain in females. Since the liver and heart of the offspring of the PRF dams were in proportion to the reduction in total body weight, the lower weight of these offspring may reflect primarily reduction in somatic growth and cannot be attributed solely to any effect on deposition of fat in adipose tissue. The lower weight gain in the PRF offspring did not appear to be due to reduced food intake. The present findings are in agreement with previous reports of the effect of increased maternal folic acid intake during pregnancy on fetal weight and length ${ }^{27}$ and the effect of supplementation of a $9 \%$ PR diet with glycine, but not alanine or urea, on body weight at 4 weeks of age, although the brain and liver were heavier than controls ${ }^{20}$. This normalisation of at least some aspects of macronutrient metabolism, and measures of vascular function ${ }^{21-23}$ and the regulation of gene expression ${ }^{18}$ at the expense of growth, may be analogous to developmental trade-offs in other species?. One possible explanation for such effects is differences between MD in the fate of metabolites involved in one-carbon metabolism. DNA methylation is only one reaction of a number of interrelated pathways involving folate including inter-conversion of methionine and homocysteine, and purine and pyrimidine biosynthesis. Mathematical modelling of these pathways shows that changes in the availability of metabolites including methionine, glycine, serine and folate induce shifts in the balance between relative activities of DNA methylation, and purine and pyrimidine synthesis ${ }^{34,35}$. Since increasing folate or glycine intake prevents reduced DNA methyltransferase-1 expression $^{19}$, the increase in the use of methyl groups for DNA methylation may be at the expense of purine and pyrimidine biosynthesis and so constrain growth by limiting capacity for DNA synthesis. If so, this implies that interactions between different pathways within one-carbon metabolism are determined during the development of the fetus and persist into adulthood.

Overall, the present findings show that the relative intakes of protein and folic acid during pregnancy in the rat induce different patterns of growth and metabolic response in the offspring, although the relative impact of MD compared to sex 
and PWD differed between metabolites. These observations are in general agreement with the opposing effects of consumption of meat and green vegetables during pregnancy on systolic blood pressure and cortisol concentrations in children $^{36,37}$. One possible implication of the present findings is that nutritional interventions to increase folic acid intake in man may need to be supported by investigation of the effects of the background diet on health outcomes.

\section{Acknowledgements}

The study was supported by a Research Fellowship awarded to G. C. B. by the British Heart Foundation. M. A. H. is also supported by the British Heart Foundation. We are grateful for the assistance of the staff of the Biomedical Research Facility, University of Southampton and to Dr J. Jackson and Mr C. J. Gelauf for assistance with the analysis of metabolites in blood.

\section{References}

1. Gluckman PD \& Hanson MA (2004) Living with the past: evolution, development, and patterns of disease. Science 305, $1733-1736$.

2. Gluckman PD, Hanson MA \& Spencer HG (2005) Predictive adaptive responses and human evolution. Trends Ecol Evol 20, $527-533$.

3. Leimar O, Hammerstein P \& Van Dooren TJ (2006) A new perspective on developmental plasticity and the principles of adaptive morph determination. Am Nat 167, 367-376.

4. Bateson P, Barker D, Clutton-Brock T, Deb D, D'Udine B, Foley RA, Gluckman P, Godfrey K, Kirkwood T, Lahr MM, McNamara J, Metcalfe NB, Monaghan P, Spencer HG \& Sultan SE (2004) Developmental plasticity and human health. Nature 430, 419-421.

5. Godfrey KM \& Barker DJ (1995) Maternal nutrition in relation to fetal and placental growth. Eur J Obstet Gynecol Reprod Bol 61, 15-22.

6. Godfrey KM \& Barker DJ (2001) Fetal programming and adult health. Public Health Nutr 4, 611-624.

7. Gluckman PD, Hanson MA \& Beedle AS (2007) Early life events and their consequences for later disease: a life history and evolutionary perspective. Am J Hum Biol 19, 1-19.

8. Jasienska G, Ziomkiewicz A, Lipson SF, Thune I \& Ellison PT (2006) High ponderal index at birth predicts high estradiol levels in adult women. Am J Hum Biol 18, 133-140.

9. Roff DA, Mostowy S \& Fairbairn DJ (2002) The evolution of trade-offs: testing predictions on response to selection and environmental variation. Evol Int J Org Evol 56, 84-95.

10. Gluckman PD \& Hanson MA (2005) The Fetal Matrix: Evolution, Development and Disease. Cambridge: Cambridge University Press.

11. Bertram CE \& Hanson MA (2001) Animal models and programming of the metabolic syndrome. Br Med Bull 60, $103-121$.

12. Armitage JA, Lakasing L, Taylor PD, Balachandran AA, Jensen RI, Dekou V, Ashton N, Nyengaard JR \& Poston L (2005) Developmental programming of aortic and renal structure in offspring of rats fed fat-rich diets in pregnancy. J Physiol 565, $171-184$.

13. Vickers MH, Gluckman PD, Coveny AH, Hofman PL, Cutfield WS, Gertler A, Breier BH \& Harris M (2005) Neonatal leptin treatment reverses developmental programming. Endocrinology 146, 4211-4216.
14. Langley SC \& Jackson AA (1994) Increased systolic blood pressure in adult rats induced by fetal exposure to maternal low protein diets. Clin Sci (Lond) 86, 217-222.

15. Burns SP, Desai M, Cohen RD, Hales CN, Iles RA, Germain JP, Going TC \& Bailey RA (1997) Gluconeogenesis, glucose handling, and structural changes in livers of the adult offspring of rats partially deprived of protein during pregnancy and lactation. $J$ Clin Invest 100, 1768-1774.

16. Ghosh P, Bitsanis D, Ghebremeskel K, Crawford MA \& Poston L (2001) Abnormal aortic fatty acid composition and small artery function in offspring of rats fed a high fat diet in pregnancy. $J$ Physiol 533, 815-822.

17. Burdge GC, Phillips ES, Dunn RL, Jackson AA \& Lillycrop KA (2004) Effect of reduced maternal protein consumption during pregnancy in the rat on plasma lipid concentrations and expression of peroxisomal proliferator-activated receptors in the liver and adipose tissue of the offspring. Nutr Res 24, 639-646.

18. Lillycrop KA, Phillips ES, Jackson AA, Hanson MA \& Burdge GC (2005) Dietary protein restriction of pregnant rats induces and folic acid supplementation prevents epigenetic modification of hepatic gene expression in the offspring. $J$ Nutr 135, $1382-1386$.

19. Lillycrop KA, Slater-Jefferies JL, Hanson MA, Godfrey KM, Jackson AA \& Burdge GC (2007) Dietary protein restriction during pregnancy in the rat alters the epigenetic regulation of the hepatic glucocorticoid receptor in the offspring by reducing DNA methyltransferase-1 expression. Br J Nutr 97, 1064-1073.

20. Burdge GC, Hanson MA, Slater-Jefferies JL \& Lillycrop KA (2007) Epigenetic regulation of transcription: a mechanism for inducing variations in phenotype (fetal programming) by differences in nutrition during early life? Br J Nutr 97, 1036-1046.

21. Jackson AA, Dunn RL, Marchand MC \& Langley-Evans SC (2002) Increased systolic blood pressure in rats induced by a maternal low-protein diet is reversed by dietary supplementation with glycine. Clin Sci (Lond) 103, 633-639.

22. Brawley L, Torrens C, Anthony FW, Itoh S, Wheeler T, Jackson AA, Clough GF, Poston L \& Hanson MA (2004) Glycine rectifies vascular dysfunction induced by dietary protein imbalance during pregnancy. J Physiol 554, 497-504.

23. Torrens C, Brawley L, Anthony FW, Dance CS, Dunn R, Jackson AA, Poston L \& Hanson MA (2006) Folate supplementation during pregnancy improves offspring cardiovascular dysfunction induced by protein restriction. Hypertension 47, 982-987.

24. Reeves PG (1997) Components of the AIN-93 diets as improvements in the AIN-76A diet. J Nutr 127, Suppl, 838S-841S.

25. Tamura $\mathrm{T} \&$ Picciano MF (2006) Folate and human reproduction. Am J Clin Nutr 83, 993-1016.

26. Burdge GC, Powell J \& Calder PC (2006) Lack of effect of meal fatty acid composition on postprandial lipid, glucose and insulin responses in men and women aged 50-65 years consuming their habitual diets. Br J Nutr 96, 489-500.

27. Achon M, Reyes L, Alonso-Aperte E, Ubeda N \& Varela-Moreiras G (1999) High dietary folate supplementation affects gestational development and dietary protein utilization in rats. J Nutr 129, 1204-1208.

28. Achon M, Alonso-Aperte E, Reyes L, Ubeda N \& Varela-Moreiras G (2000) High-dose folic acid supplementation in rats: effects on gestation and the methionine cycle. Br J Nutr $\mathbf{8 3}$, $177-183$.

29. Wolfensohn S \& Lloyd M (1998) Handbook of Laboratory Animal Management and Welfare. Oxford: Blackwell Science.

30. McGarry JD, Meier JM \& Foster DW (1973) The effects of starvation and refeeding on carbohydrate and lipid metabolism in vivo and in the perfused rat liver. The relationship between 
fatty acid oxidation and esterification in the regulation of ketogenesis. J Biol Chem 248, 270-278.

31. Fayn KN, Fielding BA \& Karpe F (2005) Adipose tissue fatty acid metabolism and cardiovascular disease. Curr Opin Lipidol 16, 409-415.

32. Bulow J, Simonsen L, Wiggins D, Humphreys SM, Frayn KN, Powell D \& Gibbons GF (1999) Co-ordination of hepatic and adipose tissue lipid metabolism after oral glucose. J Lipid Res 40, 2034-2043.

33. Dunn RL, Burdge GC \& Jackson AA (2003) Folic acid reduces blood pressure in rat offspring from maternal low protein diet but increases blood pressure in offspring of the maternal control diet. Ped Res 53, Suppl., 2A.

34. Reed MC, Nijhout HF, Neuhouser ML, Gregory JF, Shane B, James SJ, Boynton A \& Ulrich CM (2006) A mathematical model gives insights into nutritional and genetic aspects of folate-mediated one-carbon metabolism. J Nutr 136, 2653-2661.

35. Nijhout HF, Reed MC, Lam SL, Shane B, Gregory JF \& Ulrich CM (2006) In silico experimentation with a model of hepatic mitochondrial folate metabolism. Theor Biol Med Model 3, 40.

36. Shiell AW, Campbell-Brown M, Haselden S, Robinson S, Godfrey KM \& Barker DJ (2001) High-meat, low-carbohydrate diet in pregnancy: relation to adult blood pressure in the offspring. Hypertension 38, 1282-1288.

37. Herrick K, Phillips DI, Haselden S, Shiell AW, CampbellBrown M \& Godfrey KM (2003) Maternal consumption of a high-meat, low-carbohydrate diet in late pregnancy: relation to adult cortisol concentrations in the offspring. J Clin Endocrinol Metab 88, 3554-3560. 